\title{
Sarcoma of the Orbit pNX TNM Finding v7
}

National Cancer Institute

\section{Source}

National Cancer Institute. Sarcoma of the Orbit pNX TNM Finding v7. NCI Thesaurus.

Code C88818.

Sarcoma of the orbit in which the regional lymph nodes cannot be assessed. (from AJCC 7th Ed.) 